\title{
Human papillomavirus, vaccines and women's health: questions and cautions
}

\author{
Abby Lippman PhD, Ryan Melnychuk PhD, Carolyn Shimmin BJ, Madeline Boscoe RN DU
}

Published at www.cmaj.ca on Aug. I, 2007. Revised Aug. 3, 2007.

$\infty$

See related articles pages $456,462,464,469$ and 480

$\mathrm{T}$ he federal government's recently announced \$300 million investment toward a program for vaccinating girls and women with the currently available human papillomavirus (HPV) vaccine Gardasil, framed by some as a way to prevent cervical cancer in Canada, has generally been welcomed by a wide range of commentators. However, although HPV infection is necessary for the development of cervical cancer and the vaccine may prevent primary infection with HPV types I6 and I8 (currently thought to be the cause of about $70 \%$ of cervical cancer cases $^{1}$ ), we propose that these facts be assessed within a broad context before immunization policies are implemented. A careful review of the literature, including that submitted by the manufacturer with its application for approval of Gardasil, reveals a sufficient number of unanswered questions to lead us to conclude that a universal immunization program aimed at girls and women in Canada is, at this time, premature and could possibly have unintended negative consequences for individuals and for society as a whole.

In this article we summarize some of the main questions and concerns that need to be addressed before there is a fullscale rollout of an HPV vaccination program (for supplementary material go to www.cwhn.ca/resources/cwhn/hpv-brief .html). These closely reflect issues raised in the analytical framework created by Erickson and colleagues ${ }^{2}$ in the context of the development of the National Immunization Strategy and support efforts to ensure a comprehensive and systematic evaluation of all relevant factors before decisions regarding the implementation of a new immunization program are made. As well, they echo some of the research questions identified as important in the final report from the Canadian Human Papillomavirus Vaccine Research Priorities Workshop, held in Quebec City in 2005. ${ }^{3}$ We hope raising these questions now will contribute to the deliberations necessary to ensure a responsible and transparent evidence-based decision-making process.

\section{General questions and cautions}

- There is no epidemic of cervical cancer in Canada to warrant the sense of urgency for a vaccination program initi- ated by the federal finance minister's announcement. According to 2006 Canadian cancer statistics,${ }^{4}$ cervical cancer is the inth most frequent cancer affecting Canadian women and the $13^{\text {th }}$ most common cause of cancerrelated deaths, accounting for approximately 400 deaths per year. Both the incidence and mortality of cervical cancer have been declining in Canada, as in other resourcerich countries, although recently at a somewhat slower rate than has been observed in previous decades. ${ }^{5}$ However, the incidence and mortality still vary between different groups of women, being notably higher among Aboriginal women than among non-Aboriginal women.

- Invasive cervical cancer typically follows a slowly progressive course that can be halted at one of various stages. The dramatic decrease in deaths from cervical cancer in Canada, even before the development of any vaccine, represents a public health success (Figure I). Research attributes this to improved reproductive health practices and the widespread availability of publicly funded programs for Papanicolaou smear testing. ${ }^{6}$ In fact, the public funding of such programs has also significantly reduced health inequities among women. ${ }^{6}$ Consequently, deaths from cervical cancer - relatively rare in Canada but always unfortunate and not distributed evenly among women - must be considered as a failure in the adequate support of both the primary care and reproductive health services that would guarantee healthy living conditions for all women. Improvements here, as well as steps to ensure that all women receive appropriate Pap testing and follow-up, are needed.

- Most HPV infections are cleared spontaneously. Recent research using available molecular detection technologies has suggested that clearance occurs within I year for

Abby Lippman is with the Department of Epidemiology, Biostatistics, and Occupational Health, McGill University, Montréal, Que., and the Canadian Women's Health Network. Ryan Melnychuk is with the Department of Bioethics, Dalhousie University, Halifax, NS. Carolyn Shimmin is with the Canadian Women's Health Network, Winnipeg, Man. Madeline Boscoe is with the Women's Health Clinic, Winnipeg, Man. 
about $70 \%$ of infected women, and within 2 years for $90 \% .^{7}$ Thus, HPV infection and cervical cancer must not be conflated: cervical cancer will not develop in most women who are infected with even a high-risk strain of $\mathrm{HPV} .{ }^{8}$ Unfortunately, there are no data on clearance rates among girls, nor even about the actual HPV prevalence rates among youth and children, yet this is critical information for developing, and subsequently evaluating, policy proposals.

- The nature of a vaccination program is necessarily dependent on the definition of clear and tangible goals. To date, such goals have not been made explicit with regard to a Canadian initiative. Is the aim of the vaccination program the eradication of high-risk HPV types from the population? Or is it to reduce the number of deaths from cervical cancer? These different goals require different strategies. For example, pathogen eradication would imply a herd-immunity goal, thus possibly necessitating the vaccination of boys and young men. In contrast, the reduction of deaths from cervical cancer would suggest the need for a vaccine directed against more than the 2 high-risk HPV types in Gardasil, which may account for only somewhat more than two-thirds of cervical cancer cases.

- Information about the efficacy of Gardasil remains uncertain. Its real-world effectiveness is even less clear. To date, only a handful of randomized controlled trials of sufficient quality to qualify for systematic review have been reported. ${ }^{9}$ Interestingly, each of the reported HPV vaccine trials, whether of Gardasil or its potential competitor Cervarix, was funded in whole or in part by the vaccine's manufacturer. Although Rambout and colleagues, ${ }^{9}$ in their systematic review (see page 469 ), find that overall the vaccine is highly efficacious in the short term, particularly when all clinical outcomes are pooled, they also note that some methodologic weaknesses in the trial reports, combined with the limits in currently available data, continue to leave many information gaps. This situation is not unusual at this juncture in the development of new pharmaceutical products; however, it does caution against making overly optimistic descriptions of benefits and downplaying potential risks.

- We would add a number of questions to those raised by Rambout and colleagues. Specifically, what is the length of immunologic protection the vaccine confers against HPV types $\mathrm{I} 6$ and $\mathrm{I} 8$ ? Will boosters be needed to maintain this limited coverage, and if so, when? Other questions with regard to effectiveness centre on concerns about the possibility of short-term immunity altering the natural history of viral infection, as seems to be the situation with chicken pox: protection has been of shorter duration than expected, and viral infections in older people have been more severe than those in children. ${ }^{10}$

- Furthermore, we lack data on the effectiveness of the $\mathrm{HPV}$ vaccine when co-administered with other immunizations, as may occur in real practice. As well, will such factors as a person's nourishment, smoking status and general health (e.g., comorbidities) influence the safety or usefulness of the HPV vaccine? Perhaps more

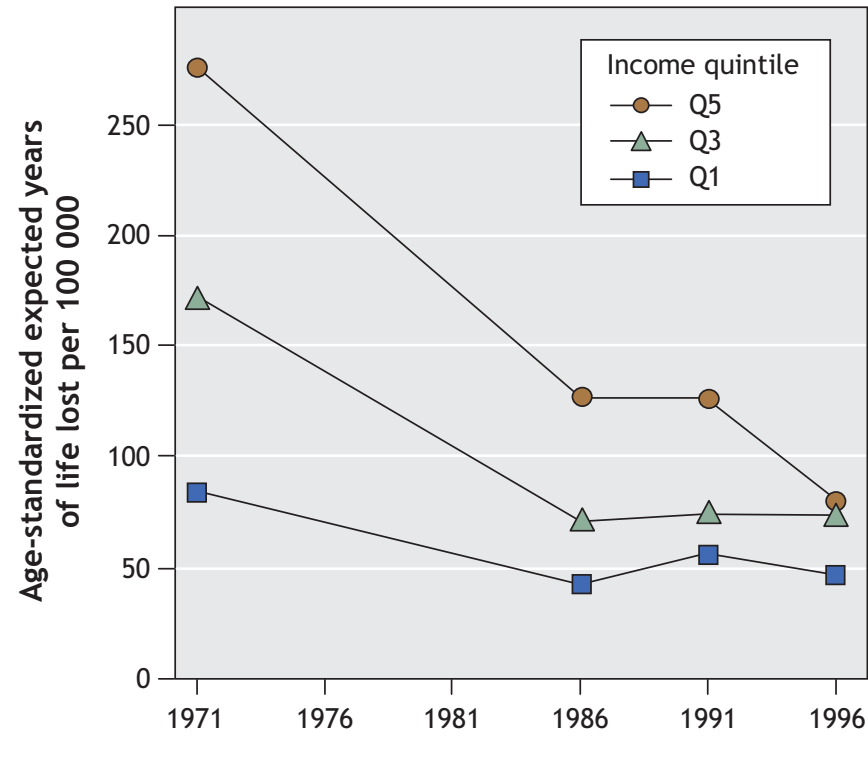

Figure 1: Avoidable mortality (age-standardized expected years of life lost per 100 ooo people) due to cervical cancer in Canada from 1971 to 1996 , by income quintile. Reproduced, with permission, from James et al. ${ }^{6}$ Copyright $\odot$ 2007, BMJ Publishing Group Ltd.

importantly, might misunderstandings about what the vaccine does and does not do lead to reductions in safer sex practices and Pap screening rates? These are among the questions raised at the Research Priorities Workshop in Quebec City in November 2005, and they remain pertinent - and unanswered.

- Relatively few girls (about I200 aged 9-I5 years) were enrolled in the clinical trials of Gardasil, the youngest of whom were followed for only 18 months. ${ }^{11}$ Based on the assumption that they will not yet have been exposed to HPV viruses, girls in this age group represent the priority target population for mass vaccination. Clearly, this is a thin information base on which to construct a policy of mass vaccination for all girls aged $9-13$, as per the National Advisory Committee on Immunization's recommendations. ${ }^{1}$

- Gardasil is the most expensive childhood vaccine proposed for mass use; it currently costs $\$ 404$ for the 3 required doses. Yet, the cost-effectiveness analyses of proposed vaccination programs needed to evaluate this expense are missing. The lack of effectiveness data makes it difficult to estimate what reduction in repeat testing or colposcopy can be anticipated to counter some of the vaccination costs and precludes determining whether vaccination will have any "added value." Girls and women, even if vaccinated, will still need to practise safer sex and have access to existing care programs for Pap testing as well as for other reproductive health care. In similar need of analysis are possible lostopportunity costs and assessments of the impact on other health care priorities of devoting limited resources to $\mathrm{HPV}$ vaccination programs. 


\section{General recommendations}

We propose a number of general recommendations that should be considered before a universal HPV vaccination program is developed and implemented (Box I).

To be clear, if and when evidence shows that an HPV vaccination program can be successfully implemented in Canada, it must be publicly funded. Lack of financial resources must not preclude any girl or woman from receiving what has been sanctioned by health officials. However, concern about how public funds are used to promote and protect the health of girls and women must consider broader issues, such as the needs of the marginalized and most vulnerable groups in society. Government support for HPV vaccinations must not perpetuate existing health inequities. Instead, such programs ought to reduce health inequities through thoughtful, comprehensive, evidence-based approaches that permit those most at risk to benefit.

To promote and protect women's health most effectively, and to work toward the prevention of deaths from cervical cancer in Canada, we should not focus only on a universal $\mathrm{HPV}$ vaccination program at this time when there is an urgent need for prompt and clear answers to the many questions outlined in this article.

Gardasil represents the first of what will likely be many vaccines targeting high-risk HPV strains, and how we proceed now will set a precedent for others. The foundation of a successful vaccination program must be solid, evidencebased research, and we now have the exciting opportunity to complete this work and develop a model for current and future HPV vaccination programs with clearly defined and measurable health outcomes. We must be certain that spending an estimated $\$ 2$ billion to vaccinate a population of girls

Box 1: General recommendations for the development of a mass vaccination program against human papillomavirus (HPV) infection

- Governments should begin immediately to educate the public about the realities of cervical cancer, HPV infection and HPV vaccinations, emphasizing the importance of healthy personal and sexual behaviour practices, good nutrition, smoking cessation, and regular Papanicolaou tests and screening for sexually transmitted infections.

- Federal, provincial and territorial policies on reproductive health care should be reviewed to assess the place of any vaccination program within existing services for the prevention and management of cervical cancer.

- The goals of any potential mass vaccination program need to be defined to ensure that the most effective and safest vaccine is used in the appropriate populations to meet these goals.

- Governments must support unbiased research, free from any conflict of interest, to collect the data now missing but essential for evidence-based policy and health care decision-making. This research needs to include studies that assess the potential impact of vaccination on safer sex practices, on access to reproductive health services and on possible lost-opportunity costs. and women in Canada who are already mostly well protected by their own immune systems, safer sex practices and existing screening programs will not perpetuate the existing gaps in care and leave the actual rate of deaths from cervical cancer unchanged. Worse would be the emergence of iatrogenic effects, such as an increase in cervical cancer rates, if a false sense of security led girls and women to stop having regular Pap screening and to view vaccination as a simple fix.

In developing a model HPV vaccination program, governments should start by educating the public about the reality of cervical cancer, HPV infection and vaccinations, to quell anxieties about cervical cancer and HPV and to emphasize the importance of healthy personal practices, including use of barrier methods, good nutrition, smoking cessation and regular Pap smears and screening for sexually transmitted infections. As well, federal, provincial and territorial policies for reproductive health care should be reviewed, including an assessment of the place of any vaccination program within existing services for the prevention and management of cervical cancer.

The latter will require a definition of the goals of any potential mass vaccination program. If the aim is cervical cancer reduction, then the possibility of favouring safe and effective vaccines that cover a broad range of high-risk viral strains should be considered. If the objective is to eliminate HPV infections, then data on how to include boys and men as well as girls and women, and how to manage newly identified oncogenic HPV types within an immunization program, are essential. Head-to-head comparisons of different vaccines carried out in unbiased research programs free of conflict of interest will be most useful here to obtain data for evidence-based policy and health care decision-making.

Canada already has thoughtful and useful frameworks for developing vaccination and cancer prevention policies. Their use in amassing and evaluating the scientific (molecular, epidemiologic, immunologic) and social evidence related to HPV vaccines, and for assessing potential benefits and harms expected from widespread immunization with the HPV vaccine, is urgent before governments allocate huge sums of already limited health care dollars to such programs. It is time to take a breath and reflect on what we know and what we don't know, and to develop a plan based on solid, reliable evidence that adds value for everyone. Individual girls and women, as well as policy-makers, can make truly informed decisions about vaccinations only when they have all the evidence, and today, there are more questions than answers.

\section{This article has been peer reviewed.}

Competing interests: None declared.

Acknowledgements: We thank Judy Norsigian, Robin Barnett and Hans Krueger, as well as members of Women and Health Protection, for their thoughtful contributions.

All of the authors are members of the Canadian Women's Health Network Writing Group and have collaborated, and shared texts, with these and other individuals and groups during the development of this material. Women and Health Protection and the Canadian Women's Health Network are both supported by the Women's Health Contribution Program, Health Canada. The opinions expressed in this article are those of the authors and not necessarily those of Health Canada. 


\section{REFERENCES}

I. National Advisory Committee on Immunization. Statement on human papillomavirus vaccine. Can Commun Dis Rep 2007;33(ACS-2):I-3I. Available: www.phac -aspc.gc.ca/publicat/ccdr-rmtc/o7pdf/acs33-02.pdf (accessed 2007 July 17).

2. Erickson LJ, De Wals P, Farand L. An analytical framework for immunization programs in Canada. Vaccine 2005;23:2470-6.

3. Public Health Agency of Canada. Canadian human papillomavirus vaccine research priorities workshop: final report. Can Commun Dis Rep 2006;32SI:I-66. Available: www.phac-aspc.gc.ca/publicat/ccdr-rmtc/o6vol32/32si/index.html (accessed 2007 July 17)

4. Canadian Cancer Society and National Cancer Institute of Canada. Canadian cancer statistics 2006. Toronto: The Institute; 2006.

5. Sellors JW, Lytwyn A. Human papilloma virus. [In: National goals for the prevention and control of sexually transmitted diseases in Canada.] Can Commun Dis Rep I997 Nov; 23 S6. Available: www.phac-aspc.gc.ca/publicat/ccdr-rmtc/97vol 23 /23s6nat/23s6g_e.html (accessed 2007 July I7).

6. James PD, Wilkins R, Detsky AS, et al. Avoidable mortality by neighbourhood income in Canada: 25 years after the establishment of universal health insurance. $J$ Epidemiol Community Health 2007;6r:287-96.

7. Management and treatment of specific infections: genital human papillomavirus
(HPV) infections. In: Canadian guidelines on sexually transmitted infections, 2006 edition. Ottawa: Public Health Agency of Canada; 2006. Available: www.phac-aspc .gc.ca/std-mts/sti_2006/sti_intro2006_e.html (accessed 2007 July 23).

8. Public Health Agency of Canada. What everyone should know about human papillomavirus (HPV): questions and answers. Available: www.phac-aspc.gc.ca/std-mts /hpv-vph/hpv-vph-qaqr_e.html (accessed 2007 July I7).

9. Rambout L, Hopkins L, Hutton B, et al. Prophylactic vaccination against human papillomavirus infection and disease in women: a systematic review of randomized controlled trials. CMAJ 2007;177:469-79.

Io. Chaves SS, Gargiullo P, Zhang JX, et al. Loss of vaccine-induced immunity to varicella over time. N Engl JMed 2007;356:II2I-9.

II. Rabin R. A new vaccine for girls: But should it be compulsory? New York Times 2006 Jul I8. Available: http://query.nytimes.com/gst/fullpage.html?sec=health\&res $=9 E_{0} 6 \mathrm{E}_{7} \mathrm{DF} 6_{3} \mathrm{FF}_{93} \mathrm{BA} 25754$ CoA9609C8B63 (accessed 2007 July 23).

Correspondence to: Dr. Abby Lippman, Department of Epidemiology, Biostatistics, and Occupational Health, McGill University, IO2O av. des Pins Ouest, Montréal QC H3A IA2; fax 5I4 398-4503; abby.lippman@mcgill.ca

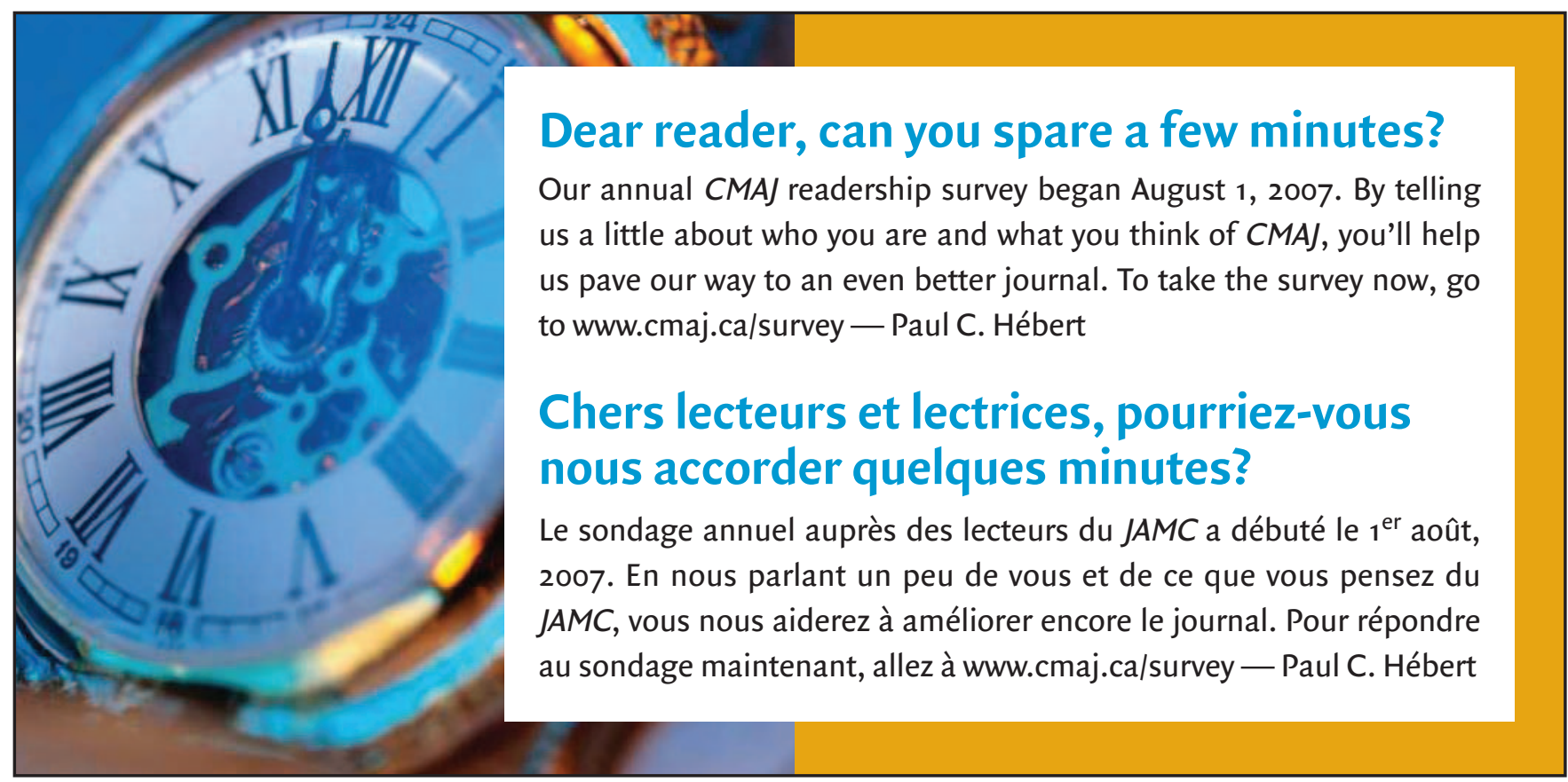

